Note

\title{
Kinetic Analysis of the Antifungal Activity of Heated Scallop-Shell Powder against Trichophyton and Its Possible Application to the Treatment of Dermatophytosis
}

\author{
JUN SAWAI*, AND HIROKAZU SHIGA \\ Department of Applied Bioscience, Faculty of Engineering, Kanagawa Institute of Technology, \\ 1030 Shimo-Ogino, Atsugi, Kanagawa 243-0292,
}

Received 8 February 2006/Accepted 14 April 2006

The antifungal activity of scallop-shell powder heated at $1000{ }^{\circ} \mathrm{C}$ for $1 \mathrm{~h}$ against Trichophyton was kinetically investigated and the possibility of applying the powder to the treatment of dermatophytosis was examined. The death rate of T. mentagrophytes NBRC5466 in the heated shell powder slurry increased with powder concentration, following first-order reaction kinetics. Elevated slurry temperatures increased both the apparent first-order death rate constant $(k)$ and the dilution coefficient $(n)$ representing the dependence of $k$ on reagent concentration. The activation energy for the death of NBRC5466 was almost equal to that for bacteria, whereas the $n$ value was much smaller than that for bacteria. In addition, the trial using heated shell powder treatment on feet showed the possibility of its application to treat dermatophytosis.

Key words : Scallop-Shell Powder/Calcium Oxide/Antifungal Activity/Trichophyton/

Death Rate Constant

Shell powder heated at a high temperature has been found to exhibit antimicrobial activity (Isshiki et al., 1994; Bari et al., 1999; Sawai et al., 2001a). The main component of shells is $\mathrm{CaCO}_{3}$, and the antimicrobial activity originates from the generation of $\mathrm{CaO}$ upon heating (Sawai et al., 1995). The present authors have reported that scallop-shell powder heated at $\geqq 700{ }^{\circ} \mathrm{C}$ exhibits antibacterial activity, and the activity of the powder heated at $1000^{\circ} \mathrm{C}$ is comparable to that of pure $\mathrm{CaO}$ (Sawai et al., 2001a; 2003). Moreover, these heated scallop-shell powder treatments were found to effectively reduce bacterial counts in vegetables (Sawai et al., 2001b). Bari et al. (2002) also reported that heated oyster-shell powder killed Escherichia coli 0157:H7, Salmonella and Listeria on the surface of tomatoes. Therefore, heated shell powder is expected to be useful in various fields such as food processing, environmental preservation

${ }^{*}$ Corresponding author. Tel \& Fax : +81-46-291-3193 and medical treatment.

In our previous study (Sawai and Yoshikawa, 2004), we demonstrated that $\mathrm{CaO}$, the main component of heated scallop-shell powder, exhibited antifungal activity against Aspergillus niger and Rhizopus stolonifer, and was more effective against fungi than bacteria. With the increase in the number of reported fungal infections in Japan and the large number of people (11-15 million) estimated to be suffering from tinea pedis (Maruyama et al., 1998), heated scallop-shell powder may be useful for the treatment of dermatophytosis. In this study, the antifungal activity of heated scallop-shell powder against Trichophyton is kinetically analyzed in a fundamental investigation of the clinical properties of this preparation. Additionally, the effect of the treatment of foot immersion in a heated scallop-shell powder slurry is investigated.

T. mentagrophytes NBRC5466, T. mentagrophytes NBRC5809, T. rubrum NRBC5467, and T. rubrum NBRC50876 were used as test microorganisms. 
These strains were subcultured on Potato Dextrose Agar (PDA; Eiken Chemicals, Tokyo, Japan) slants at $28^{\circ} \mathrm{C}$ for 10 days, and thereafter stored at $4^{\circ} \mathrm{C}$. The fungi were inoculated on PDA slants and incubated at $28^{\circ} \mathrm{C}$ for 10 days. The spores formed were collected by adding $10 \mathrm{ml}$ of $0.05 \%$ Aerosol-OT (AOT) (di-2ethylhexyl sodium sulfosuccinate: Nacalai Tesque, Inc., Kyoto, Japan) solution into the test tube containing the slant. The spores were washed once in $0.05 \%$ AOT solution by centrifugation and resuspended in a $1 \mathrm{ml}$ AOT solution.

Powdered scallop shell (Patinopecten yessoensis) was obtained from Yaizu Suisan Kagaku Industry Co., Ltd. (Yaizu, Japan). The powder was heated at 1000 ${ }^{\circ} \mathrm{C}$ in air for $1 \mathrm{~h}$, and then ground in a ball mill. The mean particle size of the heated shell powder was approximately $5 \mathrm{~mm}$. The elemental composition of the heated scallop-shell powder was described in our previous study (Sawai et al., 2001a): it contained 70.8 wt $\%$ calcium, with $99 \% \mathrm{CaO}$ by weight. The powder was mixed with sterile saline $(0.85 \mathrm{w} / \mathrm{v} \%)$ to produce a slurry.

PDA plates containing the heated scallop-shell powder at a concentration of $10 \mathrm{mg} / \mathrm{ml}$ were streaked with the four test fungi from the incubated slants using a platinum loop, and the plates were incubated at $28^{\circ} \mathrm{C}$ for 7 days. A plate without the powder (control) was also inoculated with the fungi and incubated.

Figure 1 shows the growth of Trichophyton on the PDA plate containing the powder at a concentration of $10 \mathrm{mg} / \mathrm{ml}$ (left plate). In our previous study (Sawai and Yoshikawa, 2004), $\mathrm{CaO}$ completely inhibited the fungal growth of $A$. niger and $R$. stolonifer at concentrations higher than approximately $2 \mathrm{mg} / \mathrm{ml}$. Compared with the control plate (right plate), no growth of any of the four Trichophyton strains was

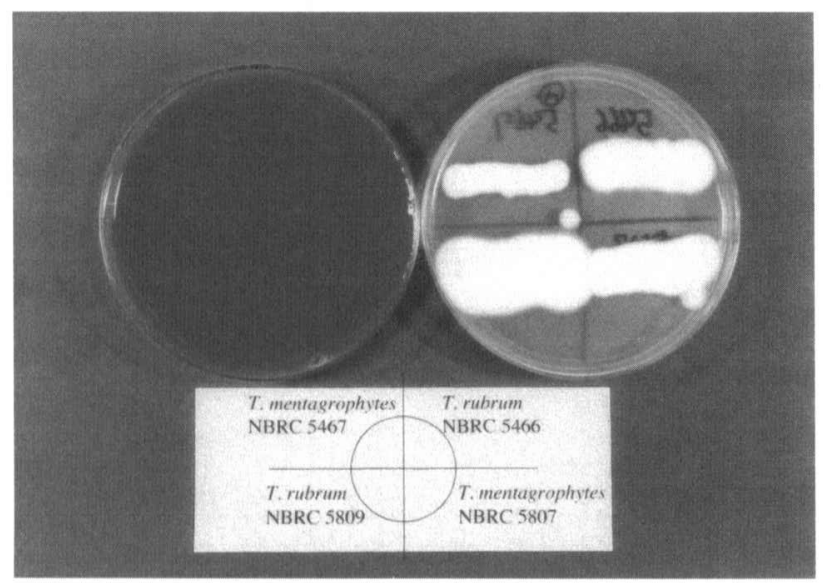

FIG. 1. Antifungal activity of heated scallop-shell powder against Dermatophytes. observed on the PDA plate containing the powder, demonstrating the antifungal activity of the heated scallop-shell powder against Trichophyton.

However, because the powder could not be dispersed uniformly in the agar due to the low solubility of the powder, shaken flask experiments were performed in order to understand the antifungal activity of the heated scallop-shell powder against Trichophyton quantitatively. T. mentagrophytes NBRC5466 was used as the test fungus in all subsequent experiments.

The powder slurry $(20 \mathrm{ml})$ was poured into a vial with an internal diameter of $42 \mathrm{~mm}$ and shaken at 110 strokes/min. The slurry temperature was controlled using a water bath. The spore suspension was aseptically pipetted into the slurry at an initial concentration of approximately $10^{5} \mathrm{CFU} / \mathrm{ml}$. Samples $(100 \mu \mathrm{l})$ were periodically withdrawn, diluted in $0.05 \%$ peptone solution, and incubated on a PDA plate. The colonies were counted after incubation at $28^{\circ} \mathrm{C}$ for 7 days. All experiments were carried out in triplicate on three different occasions. The average values were plotted in the figures, and the relative standard deviation was less than $25 \%$.

Figure 2 shows the variation in the viable spore number of $T$. mentagrophytes NBRC5466 in the

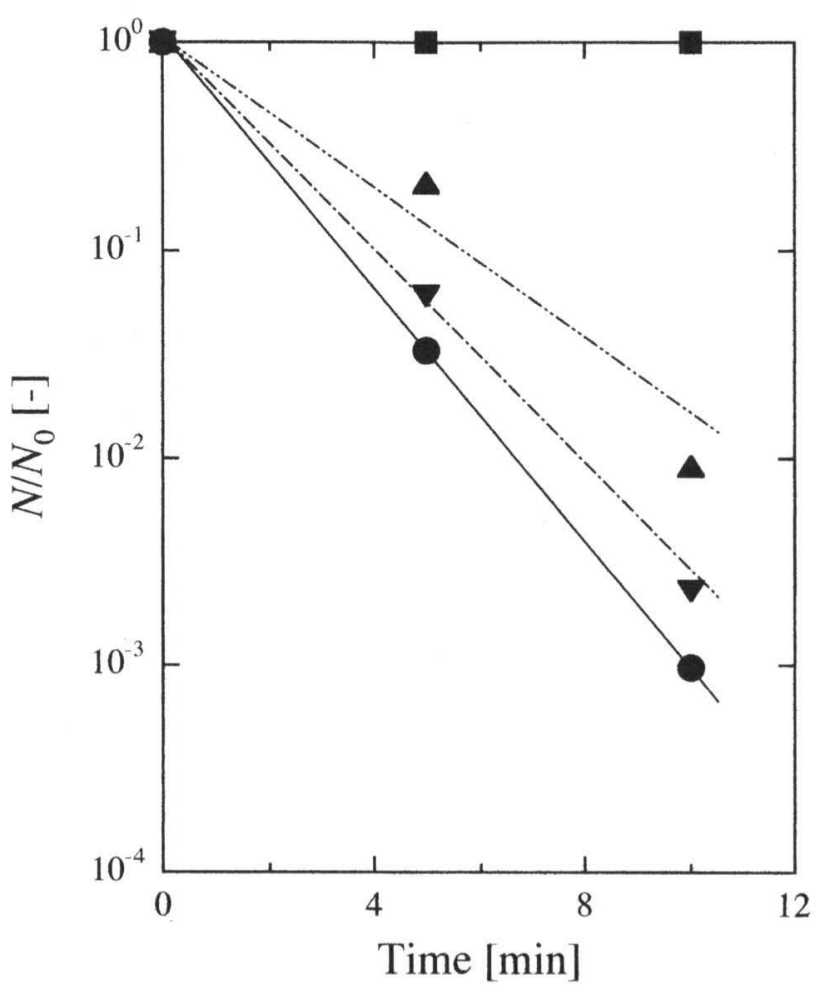

FIG. 2. Effect of the powder concentration on the survival ratio of $T$. mentagrophytes NBRC5466 exposed to heated scallop-shell powder at $35^{\circ} \mathrm{C}$. $\mathbf{D}$ : control, $\mathbf{\Delta}$ : $1 \mathrm{mg} / \mathrm{ml}$, V: $3 \mathrm{mg} / \mathrm{ml}$, : $5 \mathrm{mg} / \mathrm{ml}$. 
heated scallop-shell powder slurry at various concentrations. The ordinate denotes the ratio of the number of treated spores $(N)$ to that of the control $\left(N_{0}\right)$. The slurry temperature was $35^{\circ} \mathrm{C}$. The antifungal activity of the heated scallop-shell powder increased with powder concentration.

The temperature was found to significantly affect the antifungal activity of the heated shell powder slurry on $T$. mentagrophytes NBRC5466 (Fig. 3). At $42^{\circ} \mathrm{C}$, a hundred-fold reduction in the $N / N_{0}$ was observed within $1 \mathrm{~min}$. On a logarithmic survival ratio vs. treatment time plot, $N / N_{0}$ decreased almost linearly. Assuming that the death of $T$. mentagrophytes NBRC5466 by the heated scallop-shell powder slurry follows first-order reaction kinetics, the death rate is given by

$$
\mathrm{d} N / \mathrm{d} t=-k N
$$

where $k$ is the apparent first-order death rate constant. Figure 4 summarizes the $k$ values of the heated scallop-shell powder slurry against $T$. mentagrophytes NBRC5466 at various powder concentrations and temperatures. The following relationship between $k$ and reagent concentration (C) (Yanagida, 1980) is well known.

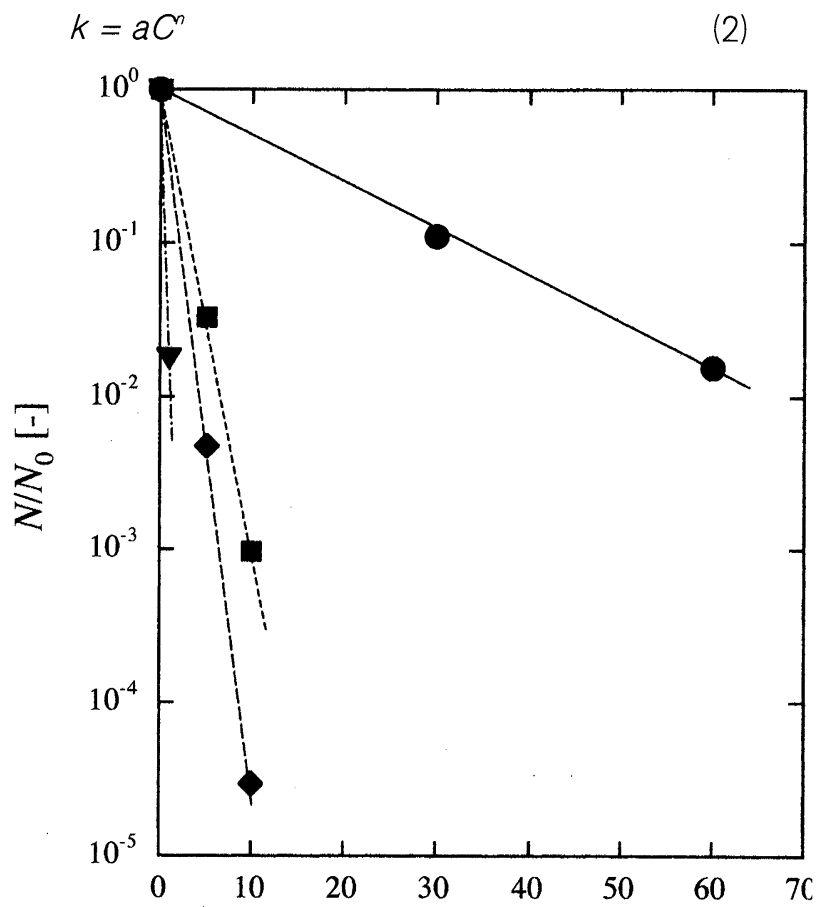

Time [min]

FIG. 3. Effect of powder slurry temperature on the antifungal activity of heated scallop-shell powder against T. mentagrophytes NBRC5466 (5mg/ml). $: 28^{\circ} \mathrm{C}, \mathbf{\square}: 35$ ${ }^{\circ} \mathrm{C}, \bullet: 40^{\circ} \mathrm{C}, \nabla: 42^{\circ} \mathrm{C}$.

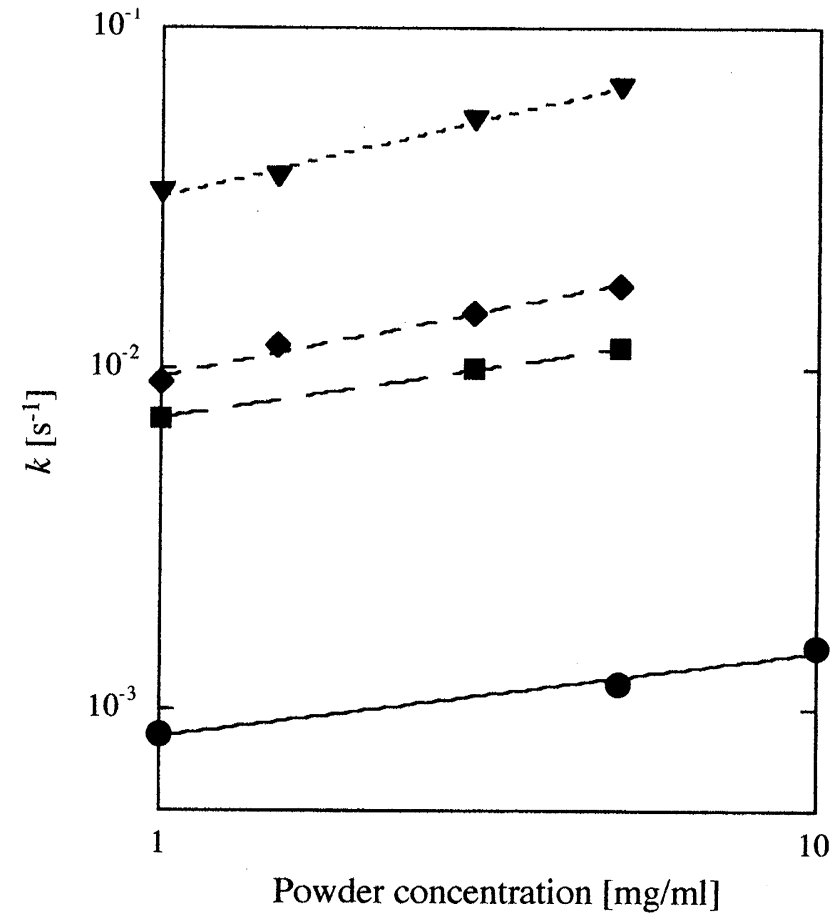

FIG. 4. Effect of the powder concentration on the death rate constant of $T$. mentagrophytes NBRC5466 exposed to heated scallop-shell powder. $: 28^{\circ} \mathrm{C}, \quad \mathbf{\square}: 35^{\circ} \mathrm{C}, \nabla: 40$ ${ }^{\circ} \mathrm{C}, \quad \nabla: 42^{\circ} \mathrm{C}$

Here, $a$ is an empirical constant and $n$ is the dilution coefficient, representing the dependence of $k$ on the powder concentration. The $n$ values, which can be obtained from the slope of the plotted lines in Fig. 4, at $18,35,40$ and $42^{\circ} \mathrm{C}$ were $0.25,0.30,0.39$, and 0.46 , respectively. The dependence of $k$ on the powder concentration increased with the temperature. The $n$ values are much smaller than those obtained for bacteria varying from 2.1 to 2.5 (Sawai et al., 2001a). This showed that the dependence of the death rate constant on the powder concentration for $T$. mentagrophytes NBRC5466 was much weaker than that for bacteria.

Figure 5 reveals that there is a good linear relationship between the values of $k$ and slurry temperature (Arrhenius plot) for $T$. mentagrophytes NBRC546. The activation energy $\left(E_{a}\right)$ required for the death of $T$. mentagrophytes NBRC546 spores when exposed to the heated scallop-shell powder was obtained from the following equation.

$$
k=A \exp \left(-E_{a} /(R T)\right)
$$

where $A, R$ and $T$ are the frequency factor, gas constant and reaction temperature, respectively. The value of $E_{\mathrm{a}}$ was estimated to be $1.9 \times 10^{5} \mathrm{~J} / \mathrm{mol}$, which is almost equal to that for bacteria (Sawai et al. 


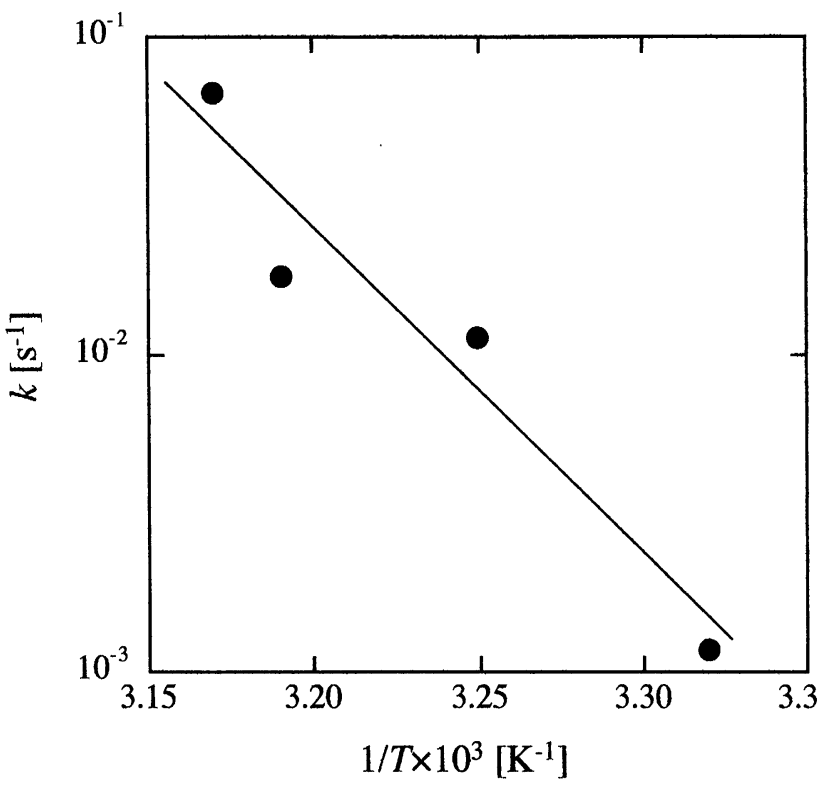

FIG. 5. Arrhenius plot of the death rate constant of $T$. mentagrophytes NBRC5466 upon exposure to a $5 \mathrm{mg}$ $\mathrm{ml}^{-1}$ slurry of heated scallop-shell powder.

\section{1a).}

The results obtained above indicate that the antifugal activity of the heated scallop-shell powder increases with temperature and the treatment at high concentrations is unnecessary because of its small $n$ value. Thus, a foot immersion treatment was conducted using a slurry with a powder concentration of $1.5 \mathrm{mg} / \mathrm{ml}$, which is a little higher than the solubility of $\mathrm{CaO}$. The slurry was prepared by pouring $2 \mathrm{~L}$ of hot water at approximately 40 to $42^{\circ} \mathrm{C}$ into a washbasin, and adding $3 \mathrm{~g}$ of the heated scallop-shell powder. Participants immersed their feet into the powder slurry for $5 \mathrm{~min}$ once a day. After immersion, the feet were rinsed in the shower. This treatment was performed daily for 10 consecutive days.

TABLE 1. Questionnaire results on the outcome of the treatment of foot immersion in a slurry of heated scallopshell powder.

\begin{tabular}{cccc}
\hline $\begin{array}{c}\text { Examminee } \\
\text { number }\end{array}$ & Sex & $\begin{array}{c}\text { Reduction } \\
\text { of itching }\end{array}$ & $\begin{array}{c}\text { Smooth feeling } \\
\text { of skin }\end{array}$ \\
\hline 1 & male & $\bigcirc$ & $\bigcirc$ \\
2 & male & $\bigcirc$ & $\bigcirc$ \\
3 & male & $\bigcirc$ & $\bigcirc$ \\
4 & female & $\bigcirc$ & $\bigcirc$ \\
5 & male & & \\
6 & male & & \\
7 & male & $\bigcirc$ & $\bigcirc$ \\
8 & male & & $\bigcirc$ \\
9 & male & $\bigcirc$ & $\bigcirc$ \\
10 & male & $\bigcirc$ & $\bigcirc$ \\
\hline
\end{tabular}

$O$ : Effective
The questionnaire results after 10 consecutive days of this treatment are summarized in Table 1. There was no aggravation of symptoms or inflammation; rather, most participants commented on the smooth feeling of their skin and the reduction of itchiness after treatment. Although a detailed microbial investigation will be required with a larger group of subjects and over a longer term, the potential for scallop-shell powder in the symptomatic treatment of dermatophyte infections has been demonstrated in this study.

\section{REFERENCES}

Bari, M.L., Kusunoki, H., Furukawa, H., Ikeda, H., Isshiki, K., and Uemura, T. (1999) Inhibition of growth of Escherichia coli 0157:H7 in fresh radish (Raphanus sativus L.) sprout production by calcinated calcium. J. Food Prot., 62, 128-132.

Bari, M.L., Inatsu, Y., Kawasaki, S., Nazuka, E., and Isshiki, K. (2002) Calcinated calcium killing of Escherichia coli 0157:H7, Salmonella, and Listeria monocytogenes on the surface of tomatoes. J. Food Prot., 65, 1706-1711.

Isshiki, K., Suhara, H., Mizuuchi, K., and Tokuoka, K. (1994) Effectiveness of calcium preparation to control microbial growth in food (in Japanese). Nippon Shokuhin Kogyo Gakkaishi, 41, 135-140.

Maruyama, R., Katoh, T., and Nishioka, K. (1998) Demonstration of dermatophyte dissemination from the infected solos using the foot-press method. Mycoses, $\mathbf{4 1}$, 1454-151.

Sawai, J., Igarashi, H., Hashimoto, A., Kokugan, T., and Shimizu, M. (1995) Evaluation of growth inhibitory effect of ceramics powder slurry on bacteria by conductance method. J. Chem. Eng. Jpn., 28, 288-293.

Sawai, J., Shiga, H., and Kojima, H. (2001a) Kinetic analysis of bactericidal action of heated scallop-shell powder. Int. J. Food Microbiol., 71, 211-218.

Sawai, J., Satoh, M., Horikawa, M., Shiga, H., and Kojima, $H$. (2001b) Heated scallop-shell powder slurry treatment of shredded cabbage. J. Food Prot., 64, 1579-1583.

Sawai, J., Miyoshi, H. and Kojima, H. (2003) Sporicidal kinetics of Bacillus subtilis spores by heated scallop shell powder. J. Food Prot., 66, 1482-1485.

Sawai, J. and Yoshikawa, T. (2004) Quantitative evaluation of antifungal activity of metallic oxide powders $(\mathrm{MgO}$, $\mathrm{CaO}$ and $\mathrm{ZnO}$ ) by an indirect conductimetric assay. J. Appl. Microbiol. 96, 803-809.

Yanagina, T. (1980) Biseibutsu Kagaku (in Japanese), Vol. 2, Gakkai Shuppan Center, Tokyo, pp. 408-412. 